\title{
Prognostic value of combined platelet, fibrinogen, neutrophil to lymphocyte ratio and platelet to lymphocyte ratio in patients with lung adenosquamous cancer
}

\author{
YU-QIAN WANG ${ }^{1-3^{*}}$, QIONG-JIE ZHI ${ }^{1-3^{*}}$, XIN-YUE WANG ${ }^{1-3}$, \\ DONG-SHENG YUE ${ }^{1,2,4}$, KAI LI ${ }^{1-3}$ and RI-CHENG JIANG ${ }^{1-3}$ \\ ${ }^{1}$ Tianjin Medical University Cancer Institute and Hospital, National Clinical Research Center for Cancer; \\ ${ }^{2}$ Key Laboratory of Cancer Prevention and Therapy; ${ }^{3}$ Department of Thoracic Oncology; ${ }^{4}$ Department of Lung Cancer, Tianjin \\ Lung Cancer Center, Tianjin Cancer Institute and Hospital, Tianjin Medical University, Hexi, Tianjin 300060, P.R. China
}

Received June 20, 2016; Accepted May 19, 2017

DOI: $10.3892 / \mathrm{ol} .2017 .6660$

\begin{abstract}
The aim of the present study was to investigate the prognostic value of the combined platelet (PLT), fibrinogen (FBG), neutrophil to lymphocyte ratio (NLR) and platelet to lymphocyte ratio (PLR) (CO-NPF) for postoperative outcomes in patients with lung adenosquamous cancer (ASC). Test results from patients who presented at The Cancer Institute and Hospital of Tianjin Medical University between January 2005 and December 2013 were retrospectively reviewed. CO-NPF was scored between 0 and 4 according to increased PLT, FBG, NLR and PLR prior to being split into two groups based on the presence $(\geq 2)$ or absence $(<2)$ of the combination of increased inflammatory indexes. In total, data from 134 patients with ASC were reviewed for the present study. Multivariate analysis identified that increased $\mathrm{CO}-\mathrm{NPF}(\mathrm{P}=0.001$ and $\mathrm{P}<0.001$, respectively), $P L R(P=0.011$ and $P=0.001$, respectively) and FBG ( $\mathrm{P}=0.001$ and $\mathrm{P}<0.001$, respectively) were independently associated with shorter disease-free survival (DFS) and overall survival $(\mathrm{OS})$. NLR $(\mathrm{P}=0.006)$ and PLT $(\mathrm{P}=0.001)$ were independent prognostic factors for OS. The area under the receiver operating characteristic curves of CO-NPF (area under the curve, $0.652, \mathrm{P}=0.008,95 \%$ confidence interval, 0.551-0.752) was increased compared with NLR, PLR, PLT and FBG individually, suggesting that CO-NPF has greater predictive value. CO-NPF was significantly and independently
\end{abstract}

Correspondence to: Dr Ri-Cheng Jiang or Dr Kai Li, Department of Thoracic Oncology, Tianjin Lung Cancer Center, Tianjin Cancer Institute \& Hospital, Tianjin Medical University, Huanhuxi Road, Hexi, Tianjin 300060, P.R. China

E-mail: jiangricheng@tjmuch.com

E-mail: likai5@medmail.com.cn

\section{*Contributed equally}

Key words: lung adenosquamous cancer, neutrophil to lymphocyte ratio, platelet to lymphocyte ratio, fibrinogen, platelet associated with shorter DFS and OS, and had greater predictive value compared with NLR, PLR, PLT and FBG in patients with ASC who underwent surgery.

\section{Introduction}

Lung cancer is a major health problem throughout the world, particularly in China $(1,2)$. Lung adenosquamous cancer (ASC) is a subtype of non-small cell lung cancer (NSCLC) that accounts for between 0.4 and $4 \%$ of all lung malignancies (3-5). ASC is defined as a carcinoma containing squamous cell carcinoma (SCC) and adenocarcinoma (ADC) components with each comprising $\geq 10 \%$ of the total tumor (6). Although the symptoms of ASC are similar to those of other histological subtypes of NSCLC (7), aggressive characteristics including early metastasis, invasiveness, rapid growth and poor prognosis have been recognized (8-10). Consequently, valuable prognostic factors are urgently needed for patients with ASC.

The association between inflammation and cancer proposed by Virchow in 1863 is now widely accepted (11). Inflammation contributes to the survival, proliferation and metastasis of cancer cells, as well as promoting angiogenesis. In addition, inflammation prevents the adaptive immune response and is able to alter responses to systemic therapies $(11,12)$. Numerous studies have revealed the association between inflammatory indexes and prognoses of patients with NSCLC, including platelet (PLT), fibrinogen (FBG), neutrophil to lymphocyte ratio (NLR) and platelet to lymphocyte ratio (PLR) (13-23). The study conducted by Unal et al (23) first identified the association between PLR and prognosis in patients with NSCLC, and suggested that assessing NLR and PLR together may predict the prognosis of patients with NSCLC. However, to the best of our knowledge, the prognostic value of these inflammatory markers for patients with ASC who have undergone surgery has not been reported. Therefore, the aim of the present study was to assess the association between NLR, PLR, PLT and FBG with the prognosis of patients with ASC and further analyze whether the combination of increased NLR, PLR, FBG and PLT (CO-NPF) was superior to any ratio alone. 
Table I. Baseline patient characteristics.

\begin{tabular}{cc}
\hline Characteristic & Number of patients \\
(of a total of 134) $(\%)$
\end{tabular}

Age, years
Median (range), 60 (34-83)
$\geq 60$
$<60$
Sex
Male
Female

Smoking index

$$
\geq 400
$$$$
<400
$$

$81(60.5)$

$53(39.5)$

$60(44.8)$

$74(55.2)$

Lymph node metastasis

Yes

$79(59.0)$

$55(41.0)$

No

$83(61.9)$

$51(38.1)$

IIIA

Operative approach

Local tumor resection

Pulmonary lobectomy

Pneumonectomy

$112(83.6)$

$10(7.5)$

Albumin, g/dl

Mean \pm SD, 43.56 \pm 5.33

$\geq 49.5$

$<49.5$

WBC count, $\times 10^{9}$ cells/ 1

Mean \pm SD, $6.98 \pm 2.94$

$\geq 5.6$

$<5.6$

99 (73.9)

$35(26.1)$

Neutrophil count, $\mathrm{x} 10^{9}$ cells/1

Mean \pm SD, $4.23 \pm 1.61$

Lymphocyte count, $\mathrm{x} 10^{9}$ cells $/ 1$

Mean \pm SD, $1.96 \pm 0.65$

\section{NLR}

Mean \pm SD, 2.36 \pm 1.13

$\geq 2.16$

$60(44.8)$

$<2.16$

$74(55.2)$

PLR

Mean \pm SD, $143.14 \pm 65.00$

$\geq 145$

$90(67.2)$

$<145$

PLT count, $\mathrm{x} 10^{9}$ cells/ 1

Mean \pm SD, 254.12 \pm 72.30

$\geq 289$

$<289$

36 (26.9)

$98(73.1)$

FBG, g/l

Mean \pm SD, 3.64 \pm 0.89

$\geq 4$

45 (33.6)

89 (66.4)
Table I. Continued.

\begin{tabular}{lc}
\hline Characteristic & $\begin{array}{c}\text { Number of patients } \\
\text { (of a total of 134) }(\%)\end{array}$ \\
\hline CO-NPF, score & \\
$<2$ & $81(60.4)$ \\
$\geq 2$ & $53(39.6)$ \\
\hline
\end{tabular}

TNM, tumor-node-metastasis; SD, standard deviation; NLR, neutrophil to lymphocyte ratio; PLR, platelet to lymphocyte ratio; PLT, platelet; FBG, fibrinogen; WBC, white blood cell; CO-NPF, combination of NLR, PLR, FBG and PLT.

\section{Patients and methods}

Study population. Patients who presented at The Cancer Institute and Hospital of Tianjin Medical University between January 2005 and December 2013 were enrolled in the present study. Demographic and clinicopathological characteristics as well as preoperative laboratory parameters were recorded and retrospectively reviewed. The study was supported by the Ethics Committee and the Institutional Review Board of The Cancer Institute and Hospital of Tianjin Medical University. Prior to enrollment into the present study, written informed consent was received from all patients or their families. The inclusion criteria were as follows: i) Histologically diagnosed with ASC; ii) with stage I-IIIA [7th Tumor-Node-Metastasis Classification of Malignant Tumors (TNM) (24)]; and iii) underwent surgery. Patients were excluded who met any of the following criteria: i) Presented with other types of carcinoma within 5 years; ii) succumbed within 1 month of surgery; iii) received adjuvant chemotherapy or radiotherapy prior to surgery; iv) suffered from active infection(s) prior to surgery; and v) lost to follow up. A total of 134 patients with ASC were recruited into the present study.

Definition of CO-NPF. NLR and PLR were defined as the ratio of neutrophils to lymphocytes and platelets to lymphocytes, respectively. According to threshold values that were determined by receiver operating characteristic (ROC) curve analysis, the NLR, PLR, PLT and FBG were each divided into two groups: $<2.16$ and $\geq 2.16,<145$ and $\geq 145,<289$ and $\geq 289$ and $<4$ and $\geq 4$, respectively. CO-NPF was defined as the combination of increased NLR, PLR, PLT and FBG. CO-NPF were scored between 0 and 4 according to the number of increased parameters (NLR, PLR, PLT and FBG). For example, patients with four increased indexes were scored 4 , whereas patients with three, two, one or zero increased indexes were scored 3, 2, 1 or 0 , respectively. CO-NPF was then divided into two groups according to the presence $(\geq 2)$ or absence $(<2)$ of the combination of increased inflammatory indexes.

Statistical analysis. Statistical analysis was performed using SPSS (version 22.0; IBM Corp., Armonk, NY, USA). Continuous data are presented as the mean \pm standard deviation or median (range), and categorical data are expressed as percentages and frequencies. Differences between two groups were 
Table II. Clinical characteristics and laboratory parameters according to CO-NPF.

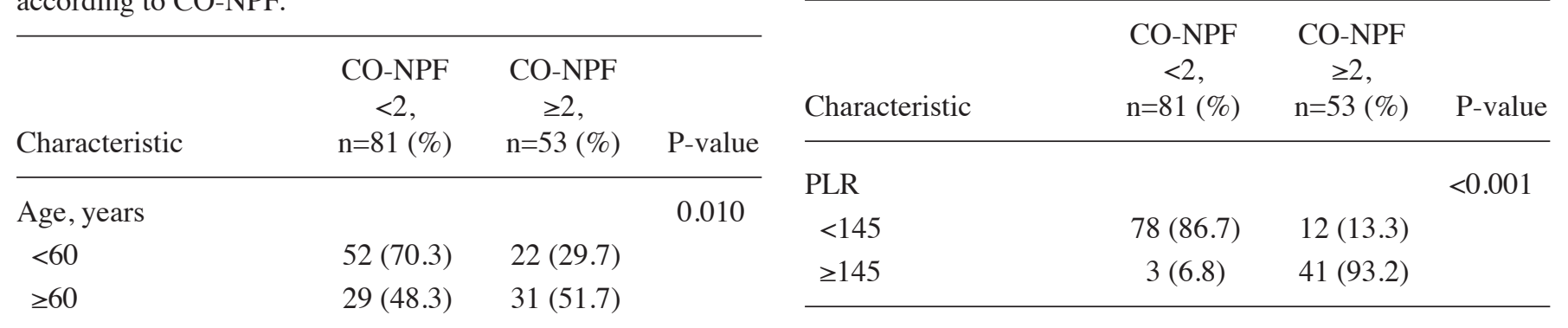

Sex

Female

Male

Smoking index

$<400$

$\geq 400$

Lymph node metastasis

Yes

No

TNM stage

I-II

IIIA

Operative approach

Local tumor resection

Pulmonary lobectomy

Pneumonectomy

WBC count, $10^{9}$ cells/1

$<5.6$

$\geq 5.6$

Neutrophil count, $10^{9}$

cells/1

$$
<3.4
$$

$\geq 3.4$

Lymphocyte count, $10^{9}$

cells/l

$$
<2.30
$$$$
\geq 2.30
$$

Monocyte count, $10^{9}$ cells/1

$$
\begin{aligned}
& <0.54 \\
& \geq 0.54
\end{aligned}
$$

PLT count, $10^{9}$

cells/1

$$
\begin{aligned}
& <289 \\
& \geq 289
\end{aligned}
$$

FBG count, g/1

$$
\begin{gathered}
<4 \\
\geq 4 \\
\text { NLR } \\
<2.16 \\
\geq 2.16
\end{gathered}
$$

\subsection{8}

TNM, tumor-node-metastasis; WBC, white blood cell; PLT, platelet; FBG, fibrinogen; NLR, neutrophil to lymphocyte ratio; PLR, platelet to lymphocyte ratio; CO-NPF, combination of NLR, PLR, FBG and PLT.
48 (48.0)

$$
29(85.3) \quad 5(14.7)
$$$$
57(67.9)
$$$$
27(32.1)
$$$$
24(48.0)
$$$$
26(52.0)
$$

0.088

0.034

0.777

0.372

0.002

44 (48.9)

0.001

0.023

$<0.001$

7 (19.4)

$71(79.8)$

18 (20.2)

10 (22.2)

35 (77.8)

$<0.001$

$\begin{array}{lr}67(90.5) & 7(9.5) \\ 14(23.3) & 46(76.7)\end{array}$
Table II. Continued.

compared using $\chi^{2}$ test or Fisher's exact test. Overall survival (OS) was defined as the period from the date of surgery to the date of mortality or censoring. Disease-free survival (DFS) was calculated from the date of surgery to the date of relapse or mortality. Kaplan-Meier estimator survival curves were created and differences between survival curves were analyzed using the log-rank test. Independent prognostic factors were identified using a multivariate Cox's regression model in which all the significant variables that were identified by univariate analysis were involved in a forward conditional manner. Hazard ratios (HRs) and 95\% confidence intervals (95\% CIs) were obtained from multivariate analysis. Areas under ROC curves (AUCs) were applied to compare NLR, PLR, PLT, FBG and $\mathrm{CO}-\mathrm{NPF}$. $\mathrm{P}<0.05$ was considered to indicate a statistically significant difference.

\section{Results}

In total, 134 patients with ASC were enrolled in the present retrospective study. For total patients, the 3-year and 5-year survival rates were 36.1 and $24.8 \%$, respectively. The median follow-up time was 22 months (range, 2-120 months) and during the follow-up period $84(61.8 \%)$ patients developed tumor relapse and 96 (70.6\%) patients succumbed. Patient baseline characteristics are summarized in Table I. The median patient age was 60 years (range, 34-83 years). Of the patient cohort, 81 $(60.5 \%)$ were male and $53(39.5 \%)$ were female. The majority of patients were stage I-II $(n=80,59.7 \%)$, with $54(40.3 \%)$ patients in stage IIIA. The majority of patients underwent pulmonary lobectomy $(\mathrm{n}=112,83.6 \%)$, with $12(8.9 \%)$ receiving local tumor resection and $10(7.5 \%)$ receiving pneumonectomy. Of the total of 134 patients, 78 (58.2\%) received platinum-based chemotherapy following surgery.

The association between clinical characteristics and laboratory parameters with CO-NPF is presented in Table II. Significant differences between CO-NPF and age $(\mathrm{P}=0.010)$, TNM stage ( $\mathrm{P}=0.034)$, neutrophil count $(\mathrm{P}=0.002)$, lymphocyte count $(\mathrm{P}=0.001)$, monocyte count $(\mathrm{P}=0.023)$, PLT count $(\mathrm{P}<0.001)$, FBG count $(\mathrm{P}<0.001), \mathrm{NLR}(\mathrm{P}<0.001)$ and $\mathrm{PLR}$ $(\mathrm{P}<0.001)$ were identified.

Univariate survival analysis results are summarized in Table III. Increased NLR ( $\mathrm{P}=0.045$ and $\mathrm{P}=0.008$, respectively), PLR ( $\mathrm{P}=0.010$ and $\mathrm{P}<0.001$, respectively), $\mathrm{PLT}(\mathrm{P}=0.042$ and 
Table III. Univariate analysis of prognostic factors influencing OS and DFS.

\begin{tabular}{|c|c|c|c|c|c|c|}
\hline \multirow[b]{2}{*}{ Characteristic } & \multicolumn{3}{|c|}{ OS } & \multicolumn{3}{|c|}{ DFS } \\
\hline & HR & $95 \% \mathrm{CI}$ & P-value & HR & $95 \% \mathrm{CI}$ & P-value \\
\hline Age, years $(\geq 60$ or $<60)$ & 1.634 & $1.093-2.444$ & 0.016 & 1.038 & $0.675-1.597$ & 0.864 \\
\hline Sex (male or female) & 0.935 & $0.620-1.411$ & 0.749 & 0.854 & $0.552-1.321$ & 0.477 \\
\hline Smoking index $(\geq 400$ or $<400)$ & 1.243 & $0.831-1.858$ & 0.288 & 0.894 & $0.579-1.381$ & 0.613 \\
\hline Lymph node metastasis (yes or no) & 1.905 & $1.243-2.918$ & 0.003 & 1.620 & $1.035-2.537$ & 0.033 \\
\hline TNM stage (I-II or IIIA) & 1.745 & $1.156-2.635$ & 0.008 & 1.878 & $1.215-2.905$ & 0.005 \\
\hline Operative approach & 1.199 & $0.744-1.933$ & 0.510 & 1.118 & $0.642-1.946$ & 0.511 \\
\hline Albumin $(\geq 49.5$ or $<49.5 \mathrm{~g} / \mathrm{dl})$ & 2.078 & $1.076-4.010$ & 0.026 & 1.978 & $0.952-4.110$ & 0.062 \\
\hline WBC count $\left(\geq 5.6\right.$ or $<5.6 \times 10^{9}$ cells $\left./ \mathrm{l}\right)$ & 1.261 & 0.799-1.992 & 0.318 & 1.118 & $0.692-1.808$ & 0.647 \\
\hline $\operatorname{NLR}(\geq 2.16$ or $<2.16)$ & 1.724 & $1.150-2.584$ & 0.008 & 1.551 & $1.005-2.395$ & 0.045 \\
\hline $\operatorname{PLR}(\geq 145$ or $<145)$ & 2.188 & $1.430-3.349$ & $<0.001$ & 1.818 & $1.146-2.884$ & 0.010 \\
\hline PLT $\left(\geq 289\right.$ or $<289 \times 10^{9}$ cells $\left./ 1\right)$ & 2.222 & $1.426-3.461$ & $<0.001$ & 1.635 & $1.012-2.642$ & 0.042 \\
\hline FBG $(\geq 4$ or $<4 \mathrm{~g} / \mathrm{l})$ & 2.131 & $1.417-3.206$ & $<0.001$ & 1.875 & $1.202-2.925$ & 0.005 \\
\hline CO-NPF $(\geq 2$ or $<2)$ & 2.187 & $1.451-3.295$ & $<0.001$ & 2.156 & $1.380-3.370$ & 0.001 \\
\hline
\end{tabular}

Operative approaches were local tumor resection, pulmonary lobectomy or pneumonectomy. TNM, tumor-node-metastasis; HR, hazard ratio; CI, confidence interval; NLR, neutrophil to lymphocyte ratio; PLR, platelet to lymphocyte ratio; PLT, platelet; FBG, fibrinogen; CO-NPF, combination of NLR, PLR, FBG and PLT; WBC, white blood cell; OS, overall survival; DFS, disease-free survival.
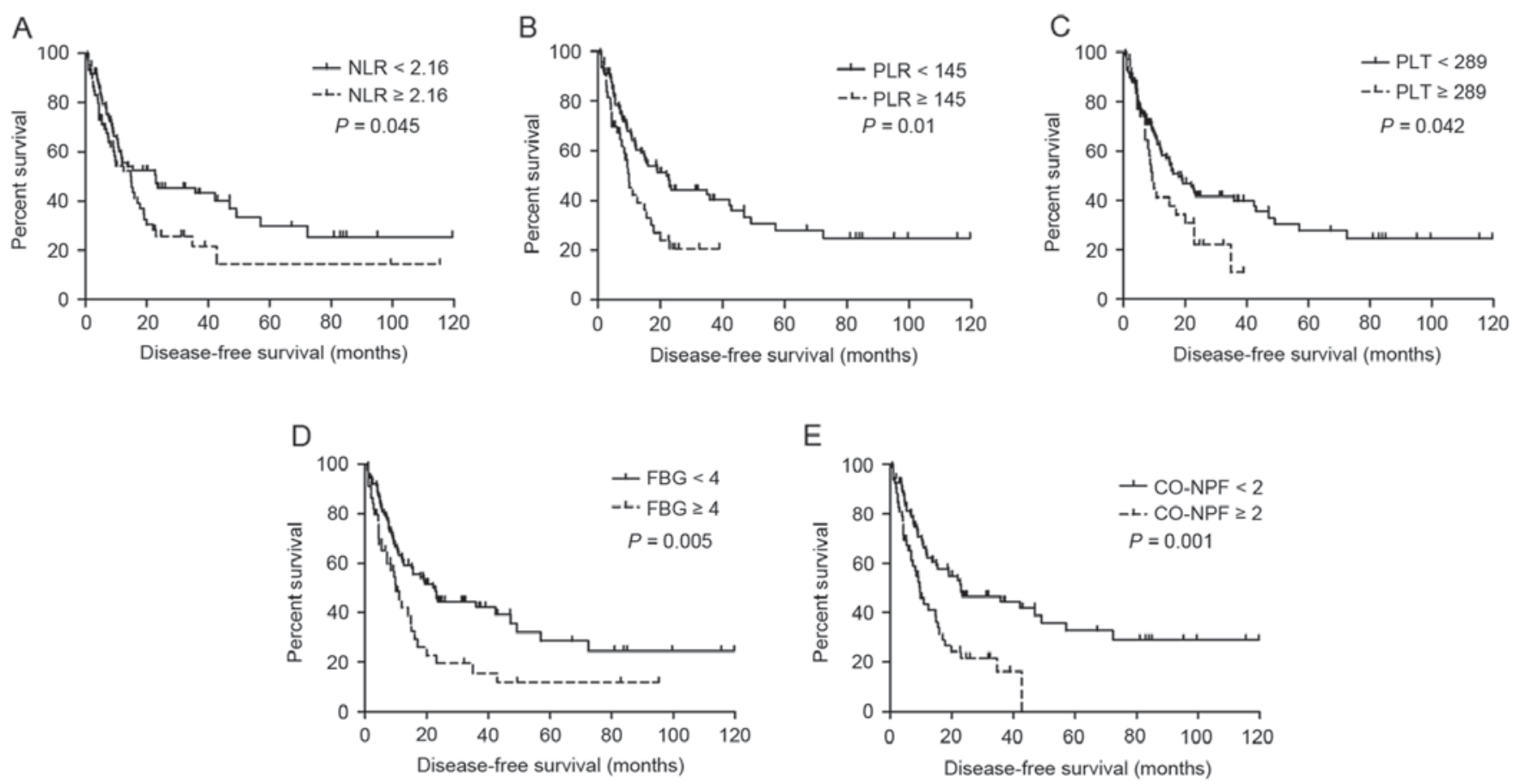

Figure 1. Kaplan-Meier estimator curves of DFS for all patients with adenosquamous cancer. DFS rates according to (A) NLR, (B) PLR, (C) PLT, (D) FBG and (E) CO-NPF. DFS, disease-free survival; NLR, neutrophil to lymphocyte ratio; PLR, platelet to lymphocyte ratio; PLT, platelet; FBG, fibrinogen; CO-NPF, combination of NLR, PLR, FBG and PLT.

$\mathrm{P}<0.001$, respectively), FBG $(\mathrm{P}=0.005$ and $\mathrm{P}<0.001$, respectively) and $\mathrm{CO}-\mathrm{NPF}(\mathrm{P}=0.001$ and $\mathrm{P}<0.001$, respectively) were significantly associated with shorter DFS (Fig. 1A-E, respectively) and OS (Fig. 2A-E, respectively). Other significant prognostic factors for DFS and OS identified included lymph node metastasis, TNM stage, age and serum albumin (all $\mathrm{P} \leq 0.05$ ).
Multivariate analysis results are presented in Table IV. CO-NPF and preoperative NLR, PLR, PLT and FBG were successively used for a multivariate Cox's regression model with other significant factors (excluding node stage) identified by univariate analyses. Increased CO-NPF $(\mathrm{P}=0.001$ and $\mathrm{P}<0.001$, respectively), PLR ( $\mathrm{P}=0.011$ and $\mathrm{P}=0.001$, respectively) and FBG $(\mathrm{P}=0.001$ and $\mathrm{P}<0.001$, respectively) were identified to be 
Table IV. Multivariate analysis of prognostic factors influencing OS and DFS.

\begin{tabular}{|c|c|c|c|c|c|c|}
\hline \multirow[b]{2}{*}{ Factor } & \multicolumn{3}{|c|}{ OS } & \multicolumn{3}{|c|}{ DFS } \\
\hline & HR & $95 \% \mathrm{CI}$ & P-value & HR & $95 \% \mathrm{CI}$ & P-value \\
\hline \multicolumn{7}{|l|}{ Model 1} \\
\hline Age, years $(\geq 60$ or $<60)$ & 1.586 & $1.039-2.423$ & 0.033 & & & \\
\hline Albumin $(\geq 49.5$ or $<49.5 \mathrm{~g} / \mathrm{dl})$ & 3.037 & $1.528-6.033$ & 0.003 & & & \\
\hline TNM stage (I-II or IIIA) & & & & 1.602 & $1.019-2.517$ & 0.041 \\
\hline CO-NPF $(\geq 2$ or $<2)$ & 2.177 & $1.420-3.337$ & $<0.001$ & 1.904 & $1.210-3.020$ & 0.006 \\
\hline \multicolumn{7}{|l|}{ Model 2} \\
\hline Age, years $(\geq 60$ or $<60)$ & 1.814 & $1.196-2.752$ & 0.005 & & & \\
\hline Albumin $(\geq 49.5$ or $<49.5 \mathrm{~g} / \mathrm{dl})$ & 2.731 & $1.357-5.494$ & 0.005 & & & \\
\hline TNM stage (I-II or IIIA) & 1.621 & $1.069-2.460$ & 0.023 & 1.878 & $1.215-2.905$ & 0.005 \\
\hline NLR $(\geq 2.16$ or $<2.16)$ & 1.782 & $1.176-2.700$ & 0.006 & & & \\
\hline \multicolumn{7}{|l|}{ Model 3} \\
\hline Age, years $(\geq 60$ or $<60)$ & 1.738 & $1.142-2.643$ & 0.010 & & & \\
\hline Albumin $(\geq 49.5$ or $<49.5 \mathrm{~g} / \mathrm{dl})$ & 2.615 & $1.313-5.211$ & 0.006 & & & \\
\hline TNM stage (I-II or IIIA) & 1.538 & $1.006-2.351$ & 0.047 & 1.715 & $1.097-2.681$ & 0.018 \\
\hline $\operatorname{PLR}(\geq 145$ or $<145)$ & 2.005 & $1.294-3.106$ & 0.002 & 1.609 & $1.004-2.577$ & 0.048 \\
\hline \multicolumn{7}{|l|}{ Model 4} \\
\hline Age, years $(\geq 60$ or $<60)$ & 1.956 & $1.284-2.980$ & 0.002 & & & \\
\hline Albumin $(\geq 49.5$ or $<49.5 \mathrm{~g} / \mathrm{dl})$ & 2.099 & $1.046-4.214$ & 0.037 & & & \\
\hline TNM stage (I-II or IIIA) & & & & 1.878 & $1.215-2.905$ & 0.005 \\
\hline PLT $\left(\geq 289\right.$ or $<289 \times 10^{9}$ cells $\left./ 1\right)$ & 2.276 & $1.432-3.617$ & 0.001 & & & \\
\hline \multicolumn{7}{|l|}{ Model 5} \\
\hline Age, years $(\geq 60$ or $<60)$ & 1.553 & $1.009-2.389$ & 0.045 & & & \\
\hline Albumin $(\geq 49.5$ or $<49.5 \mathrm{~g} / \mathrm{dl})$ & 2.437 & $1.224-4.852$ & 0.011 & & & \\
\hline TNM stage (I-II or IIIA) & 1.716 & $1.131-2.604$ & 0.011 & 1.871 & $1.209-2.894$ & 0.005 \\
\hline FBG $(\geq 4$ or $<4 \mathrm{~g} / \mathrm{l})$ & 2.045 & $1.332-3.141$ & 0.001 & 1.865 & $1.196-2.910$ & 0.006 \\
\hline
\end{tabular}

TNM, tumor-node-metastasis; HR, hazard ratio; CI, confidence interval; NLR, neutrophil to lymphocyte ratio; PLR, platelet to lymphocyte ratio; PLT, platelet; FBG, fibrinogen; CO-NPF, combination of NLR, PLR, FBG and PLT; OS, overall survival; DFS, disease-free survival.

independently and significantly associated with shorter DFS and OS. Other independent prognostic factors for OS were NLR $(\mathrm{P}=0.006)$, $\mathrm{PLT}(\mathrm{P}=0.001)$, age $(\mathrm{P}=0.033)$ and serum albumin $(\mathrm{P}=0.003)$. TNM stage was identified to be independently associated with DFS $(\mathrm{P}<0.05)$, as presented in Table IV.

Subgroup analysis demonstrated that patients with CO-NPF $<2$ exhibited an improved prognosis compared with those with $\mathrm{CO}-\mathrm{NPF} \geq 2$. Patients with $\mathrm{CO}-\mathrm{NPF}<2$ exhibited a 3 -year OS rate of $46.9 \%$ and a 5 -year OS rate of $28.6 \%$, whereas those with $\mathrm{CO}-\mathrm{NPF} \geq 2$ exhibited a 3 -year OS rate of $17.4 \%$ and a 5 -year OS rate of $11.6 \%$. The median survival times of the two groups were 35.9 and 14.4 months, respectively $(\mathrm{P}<0.001$; Fig. $2 \mathrm{E})$. The prognostic impact of CO-NPF according to TNM stage (I-II or IIIA) was then analyzed and increased CO-NPF was identified to be significantly associated with shorter DFS and OS in the stage I-II subgroup (HR, 2.638; 95\% CI, 1.422-4.894; $\mathrm{P}=0.002$; and $\mathrm{HR}, 3.045$; $95 \% \mathrm{CI}$, 1.742-5.324; $\mathrm{P}<0.001$, respectively; Fig. 3).

Finally, by comparing the AUC, the association between NLR, PLR, PLT, FBG and CO-NPF with 3-year OS rates was assessed (Fig. 4). CO-NPF exhibited greater predictive significance (AUC, 0.652; $\mathrm{P}=0.008 ; 95 \% \mathrm{CI}, 0.551-0.752$ ) compared with NLR (AUC, 0.629; P=0.024; 95\% CI, 0.524-0.734), PLR (AUC, 0.645; P=0.011;95\% CI, 0.546-0.744), PLT (AUC, 0.624; $\mathrm{P}=0.030 ; 95 \% \mathrm{CI}, 0.524-0.724$ ) or $\mathrm{FBG}$ (AUC, 0.592; $\mathrm{P}=0.107 ; 95 \%$ CI, 0.486-0.697).

\section{Discussion}

The present retrospective study assessed the association between preoperative systemic inflammatory indexes and a novel inflammation-based marker (CO-NPF) with the postoperative prognosis of 134 patients with ASC. The results revealed that CO-NPF, NLR, PLR, PLT and FBG were independently and significantly associated with decreased OS rates. Furthermore, CO-NPF, PLR and FBG were all independent prognostic factors for DFS. CO-NPF was superior to NLR, PLR, PLT and FBG individually in predicting 3-year survival rates.

Systemic inflammatory responses may exert dual effects on cancer, promoting tumor proliferation, while inhibiting other oncogenic processes. The tumor microenvironment may 

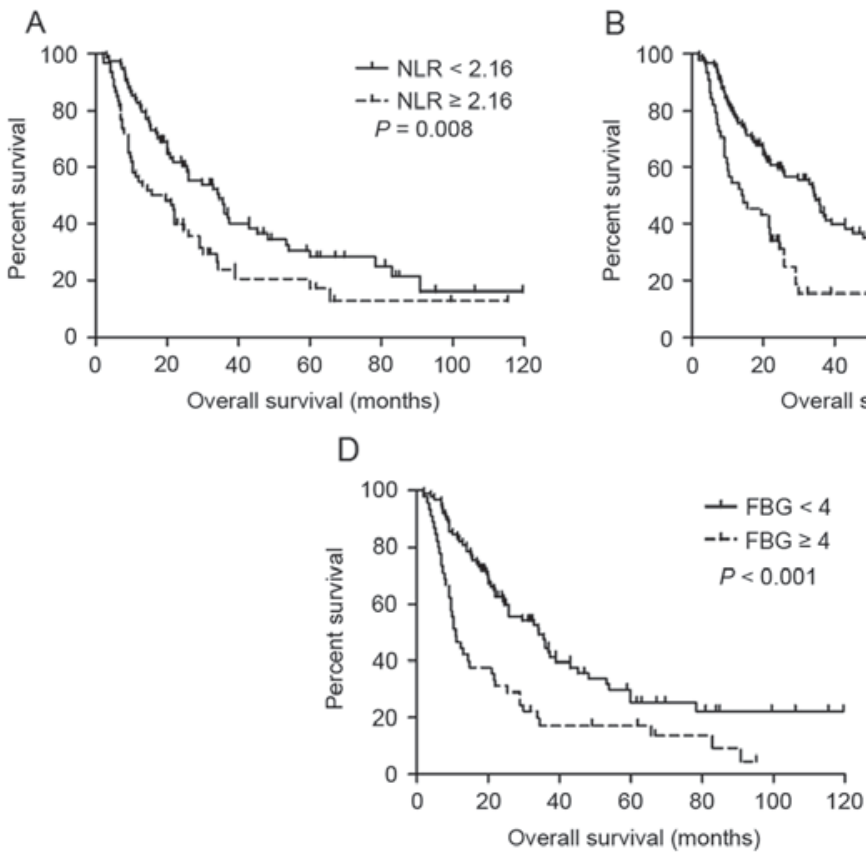
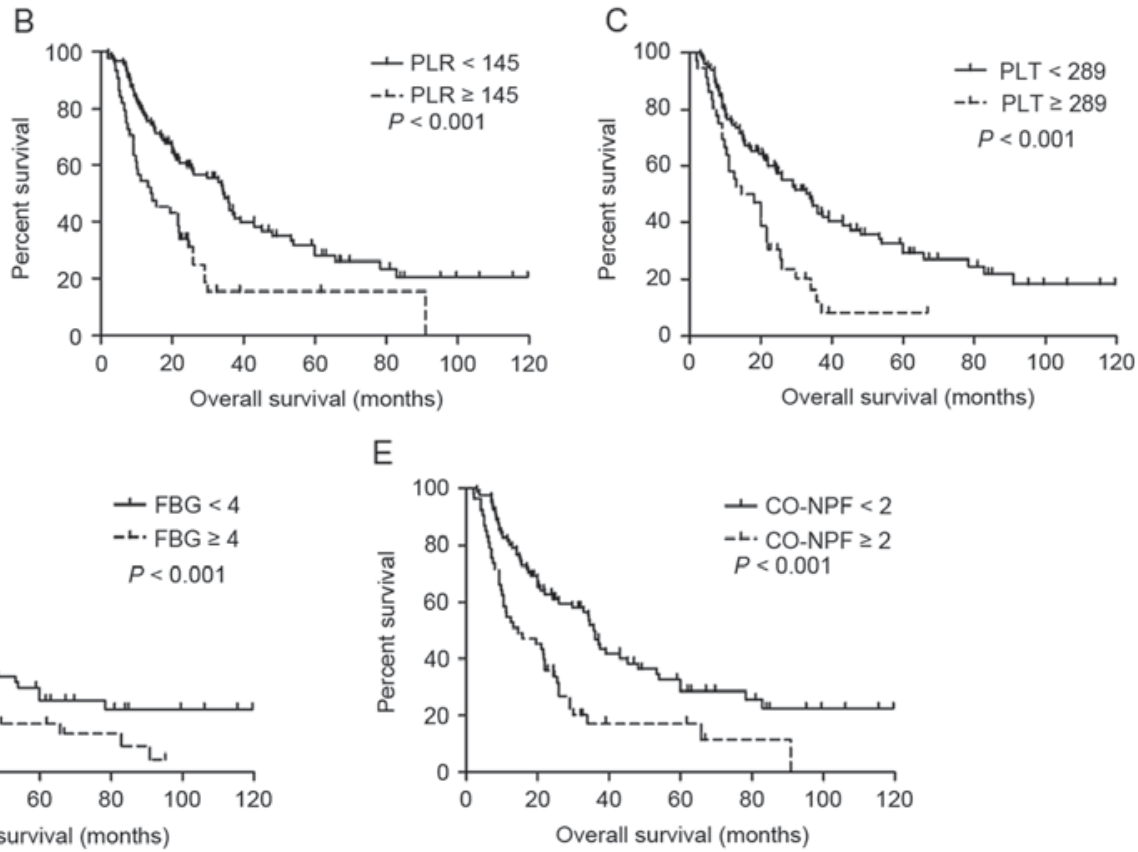

Figure 2. Kaplan-Meier estimator curves of OS for all patients with adenosquamous cancer. OS rates according to (A) NLR, (B) PLR, (C) PLT, (D) FBG and (E) CO-NPF. OS, overall survival; NLR, neutrophil to lymphocyte ratio; PLR, platelet to lymphocyte ratio; PLT, platelet; FBG, fibrinogen; CO-NPF, combination of NLR, PLR, FBG and PLT.

A

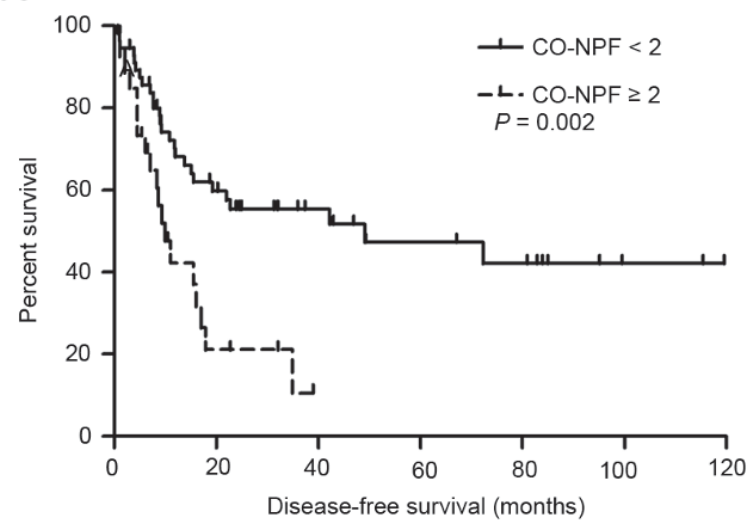

B

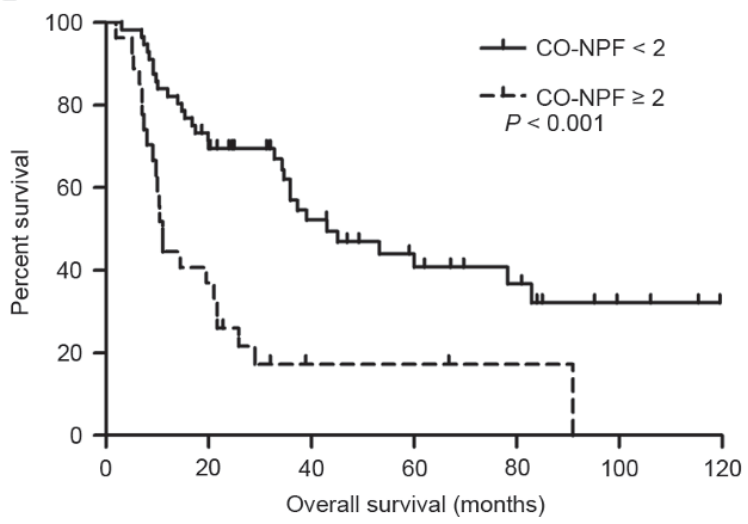

Figure 3. Kaplan-Meier estimator curves of DFS and OS rates of patients with stage I-II adenosquamous cancer according to CO-NPF. (A) DFS and (B) OS rates, according to CO-NPF of patients of TNM I-II stage. DFS, disease-free survival; OS, overall survival; CO-NPF, combination of neutrophil to lymphocyte ratio, platelet to lymphocyte ratio, fibrinogen and platelet; TNM, tumor-node-metastasis.

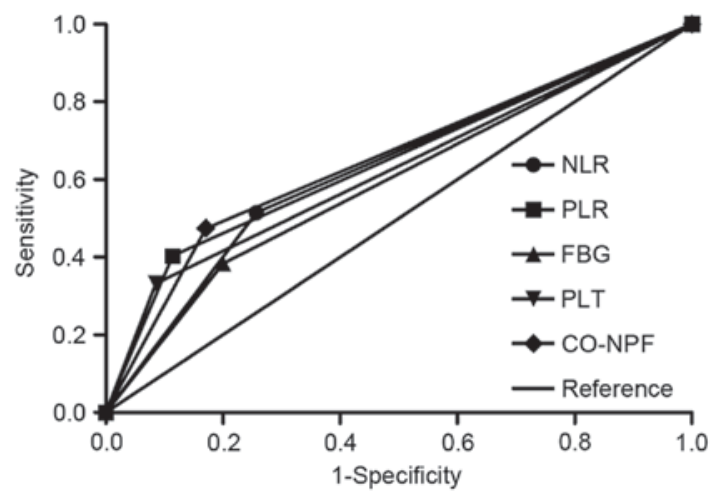

Figure 4. Area under the curve of NLR, PLR, PLT, FBG and CO-NPF. Comparison of receiver operating characteristic curves based on NLR, PLR, PLT, FBG and CO-NPF in the 3-year overall survival rate. NLR, neutrophil to lymphocyte ratio; PLR, platelet to lymphocyte ratio; PLT, platelet; FBG, fibrinogen; CO-NPF, combination of NLR, PLR, FBG and PLT. be heavily infiltrated by inflammatory cells and increased pro-inflammatory cytokines released by these cells subsequently promote tumor growth (11). For example, neutrophils are able to significantly promote angiogenesis by secreting vascular endothelial growth factor (VEGF) and tumor progression by suppressing the cytotoxic activity of lymphocytes (11). Release of growth factors, including platelet factor 4, platelet-derived growth factor, thrombospondin and VEGF by platelets promotes hematogenous cancer spread, cancer cell adhesion, invasion, angiogenesis as well as tumor progression (25-27). In addition, fibrinogen may protect tumor cells from natural killer cytotoxicity (28). Conversely, lymphocytes suppress tumor growth and invasion through their cytolytic activity (29). Increased NLR may represent increased neutrophil counts, decreased lymphocyte counts, or both. The same is true for PLR with respect to the platelet and lymphocyte association. The prognostic 
significance of NLR, PLR, PLT and FBG has been suggested in numerous types of cancer including NSCLC. Although the prognostic role of these indexes in NSCLC remains controversial, the results of the present study are in line with a clinical prognostic value. Several studies have identified that increased pretreatment NLR or PLR predicts shorter progression-free survival (PFS), DFS and OS in patients with NSCLC as well as poor response to first-line platinum-based treatment $(16,18,20)$. Furthermore, other reports suggest that increased pretreatment PLT and FBG are significantly associated with unfavorable DFS, PFS or OS in patients with NSCLC $(13-15,19,21,22)$. Although the prognostic value of NLR, PLR, PLT and FBG in NSCLC is consistent with that in ASC, the exact threshold values of these indexes have not been defined. As a result, ROC curves were used in the present study to define the optimal threshold values.

NLR, PLR, PLT and FBG all represent systemic inflammation and serve important roles in cancer. CO-NPF may serve as a promising prognostic factor defining the association between inflammation and cancer in a more comprehensive manner. Indeed, CO-NPF was superior to NLR, PLR, PLT and FBG in predicting 3-year survival rates. Notably, subgroup analysis revealed that CO-NPF was significantly associated with decreased DFS and OS rates of patients in the stage I-II subgroup, but not of those in the stage IIIA subgroup (data not shown). This implies that the prognostic value of inflammatory indexes may be influenced by the TNM stage. By analyzing the association of clinical characteristics and laboratory parameters with $\mathrm{CO}-\mathrm{NPF}$, it was revealed that there were significant differences between the two CO-NPF groups in age, TNM stage, neutrophil count, lymphocyte count, monocyte count, PLT count, FBG count, NLR and PLR. However, CO-NPF was not significantly associated with lymph node metastasis, implying that inflammation is more likely to contribute to hematogenous metastasis, which is consistent with a previous study (30).

All patients recruited in the present study were from a single center which may limit the results, thus these results require further confirmation by a multi-center study. In addition, as a retrospective study, certain useful parameters which were not routinely measured prior to surgery may have been missed. For example, $\mathrm{C}$-reactive protein measurement (30) and Glasgow Prognostic Score (31) may be used to confirm the results in a prospective study. Wu et al (32) and Kwon et al (33), respectively, demonstrated that phosphorylated insulin-like growth factor-1 receptor (pIGF1R) and mucin 4 expression were associated with the prognosis of patients with pulmonary adenocarcinoma. However, the optimum prognostic factor among CO-NPF, mucin 4 and plGF1R requires further confirmation by future studies. However, to the best of our knowledge, the present study is the first to investigate the prognostic role of PLT, FBG, NLR and PLR in patients with ASC, and the results of the present study further demonstrated that CO-NPF has improved predictive power compared with NLR, PLR, PLT and FBG individually. These inflammatory indexes are cost-effective, readily available and effective prognostic factors, with the results of the present study suggesting that assessing them together is superior to their use independently.

\section{Acknowledgements}

The authors are grateful to Dr Douglas E. Linn (Brigham \& Women's Hospital, Boston, MA, USA) for a critical reading of the paper. The present study was supported by grants from the National Natural Science Foundation of China (grant nos. 81372517 and 81000899), the Tianjin Municipal Science and Technology Commission Key Application Research Projects (grant no. 11JCZDJC18900), the National Natural Science Foundation of China (grant no. 81501983), the National Science and Technology Major Project (grant no. 2013ZX) and the Tianjin Municipal Science and Technology Commission Projects (grant nos. 11JCYBJC11300 and 12ZCDZSY15600).

\section{References}

1. Chang S, Dai M, Ren JS, Chen YH and Guo LW: Estimates and prediction on incidence, mortality and prevalence of lung cancer in China in 2008. Zhonghua Liu Xing Bing Xue Za Zhi 33: 391-394, 2012 (In Chinese).

2. Ferlay J, Shin HR, Bray F, Forman D, Mathers C and Parkin DM: Estimates of worldwide burden of cancer in 2008: GLOBOCAN 2008. In J Cancer 127: 2893-2917, 2010.

3. Fitzgibbons PL and Kern WH: Adenosquamous carcinoma of the lung: A clinical and pathologic study of seven cases. Hum Pathol 16: 463-466, 1985.

4. Ishida T, Kaneko S, Yokoyama H, Inoue T, Sugio K and Sugimachi K: Adenosquamous carcinoma of the lung. Clinicopathologic and immunohistochemical features. Am J Clin Pathol 97: 678-685, 1992.

5. Shimizu J, Oda M, Hayashi Y, Nonomura A and Watanabe Y: A clinicopathologic study of resected cases of adenosquamous carcinoma of the lung. Chest 109: 989-994, 1996.

6. Gibbs AR and Thunnissen FB: Histological typing of lung and pleural tumours: Third edition. J Clin Pathol 54: 498-499, 2001.

7. Sridhar KS, Bounassi MJ, Raub W Jr and Richman SP: Clinical features of adenosquamous lung carcinoma in 127 patients. Am Rev Respir Dis 142: 19-23, 1990.

8. Lee Y, Chung JH, Kim SE, Kim TJ and Lee KW: Adenosquamous carcinoma of the lung: CT, FDG PET, and clinicopathologic findings. Clin Nucl Med 39: 107-112, 2014.

9. Maeda H, Matsumura A, Kawabata T, Suito T, Kawashima O, Watanabe T, Okabayashi K and Kubota I; Japan National Hospital Organization Study Group for Lung Cancer: Adenosquamous carcinoma of the lung: Surgical results as compared with squamous cell and adenocarcinoma cases. Eur J Cardiothorac Surg 41: 357-361, 2012.

10. Mordant P, Grand B, Cazes A, Foucault C, Dujon A, Le Pimpec Barthes $\mathrm{F}$ and Riquet M: Adenosquamous carcinoma of the lung: Surgical management, pathologic characteristics, and prognostic implications. Ann Thorac Surg 95: 1189-1195, 2013.

11. Coussens LM and Werb Z: Inflammation and cancer. Nature 420: 860-867, 2002.

12. Mantovani A, Allavena P, Sica A and Balkwill F: Cancer-related inflammation. Nature 454: 436-444, 2008.

13. Ji Y, Sheng L, Du X, Qiu G and Su D: Elevated platelet count is a strong predictor of poor prognosis in stage I non-small cell lung cancer patients. Platelets 26: 138-142, 2015.

14. Jiang HG, Li J, Shi SB, Chen P, Ge LP, Jiang Q and Tang XP: Value of fibrinogen and D-dimer in predicting recurrence and metastasis after radical surgery for non-small cell lung cancer. Med Oncol 31: 22, 2014.

15. Kim KH, Park TY, Lee JY, Lee SM, Yim JJ, Yoo CG, Kim YW, Han SK and Yang SC: Prognostic significance of initial platelet counts and fibrinogen level in advanced non-small cell lung cancer. J Korean Med Sci 29: 507-511, 2014.

16. Kos M, Hocazade C, Kos FT, Uncu D, Karakas E, Dogan M, Uncu HG, Yildirim N and Zengin N: Prognostic role of pretreatment platelet/lymphocyte ratio in patients with non-small cell lung cancer. Wien Klin Wochenschr 128: 635-640, 2016.

17. Kwon HC, Kim SH, Oh SY, Lee S, Lee JH, Choi HJ, Park KJ, Roh MS, Kim SG, Kim HJ and Lee JH: Clinical significance of preoperative neutrophil-lymphocyte versus platelet-lymphocyte ratio in patients with operable colorectal cancer. Biomarkers 17: 216-222, 2012. 
18. Pinato DJ, Shiner RJ, Seckl MJ, Stebbing J, Sharma R and Mauri FA: Prognostic performance of inflammation-based prognostic indices in primary operable non-small cell lung cancer. $\mathrm{Br}$ J Cancer 110: 1930-1935, 2014.

19. Sheng L, Luo M, Sun X, Lin N, Mao W and Su D: Serum fibrinogen is an independent prognostic factor in operable nonsmall cell lung cancer. Int J Cancer 133: 2720-2725, 2013.

20. Yao Y, Yuan D, Liu H, Gu X and Song Y: Pretreatment neutrophil to lymphocyte ratio is associated with response to therapy and prognosis of advanced non-small cell lung cancer patients treated with first-line platinum-based chemotherapy. Cancer Immunol Immunother 62: 471-479, 2013.

21. Yu D, Liu B, Zhang L and Du K: Platelet count predicts prognosis in operable non-small cell lung cancer. Exp Ther Med 5 . 1351-1354, 2013

22. Zhu JF, Cai L, Zhang XW, Wen YS, Su XD, Rong TH and Zhang LJ: High plasma fibrinogen concentration and platelet count unfavorably impact survival in non-small cell lung cancer patients with brain metastases. Chin J Cancer 33: 96-104, 2014.

23. Unal D, Eroglu C, Kurtul N, Oguz A and Tasdemir A: Are neutrophil/lymphocyte and platelet/lymphocyte rates in patients with non-small cell lung cancer associated with treatment response and prognosis? Asian Pac J Cancer Prev 14: 5237-5242, 2013.

24. Vallières E, Shepherd FA, Crowley J, Van Houtte P, Postmus PE Carney D, Chansky K, Shaikh Z and Goldstraw P; International Association for the Study of Lung Cancer International Staging Committee and Participating Institutions: The IASLC Lung Cancer Staging Project: Proposals regarding the relevance of TNM in the pathologic staging of small cell lung cancer in the forthcoming (seventh) edition of the TNM classification for lung cancer. J Thorac Oncol 4: 1049-1059, 2009.

25. Dubernard V, Arbeille BB, Lemesle MB and Legrand C: Evidence for an alpha-granular pool of the cytoskeletal protein alpha-actinin in human platelets that redistributes with the adhesive glycoprotein thrombospondin-1 during the exocytotic process. Arterioscler Thromb Vasc Biol 17: 2293-2305, 1997.
26. Kaplan KL, Broekman MJ, Chernoff A, Lesznik GR and Drillings M: Platelet alpha-granule proteins: Studies on release and subcellular localization. Blood 53: 604-618, 1979.

27. Qian X and Tuszynski GP: Expression of thrombospondin-1 in cancer: A role in tumor progression. Proc Soc Exp Biol Med 212: 199-207, 1996

28. Zheng S, Shen J, Jiao Y, Liu Y, Zhang C, Wei M, Hao S and Zeng $X$ : Platelets and fibrinogen facilitate each other in protecting tumor cells from natural killer cytotoxicity. Cancer Sci 100: 859-865, 2009.

29. Zhang J, Huang SH, Li H, Li Y, Chen XL, Zhang WQ, Chen HG and Gu LJ: Preoperative lymphocyte count is a favorable prognostic factor of disease-free survival in non-small-cell lung cancer. Med Oncol 30: 352, 2013.

30. Zhang H, Zhang L, Zhu K, Shi B, Yin Y, Zhu J, Yue D, Zhang B and Wang $C$ : Prognostic significance of combination of preoperative platelet count and neutrophil-lymphocyte ratio (COP-NLR) in patients with non-small cell lung cancer: Based on a large cohort study. PLoS One 10: e0126496, 2015.

31. McMillan DC: The systemic inflammation-based Glasgow prognostic score: A decade of experience in patients with cancer. Cancer Treat Rev 39: 534-540, 2013.

32. Wu PF, Huang WC, Yang JC, Lu YS, Shih JY, Wu SG, Lin CH and Cheng AL: Phosphorylated insulin-like growth factor-1 receptor (pIGF1R) is a poor prognostic factor in brain metastases from lung adenocarcinomas. J Neurooncol 115: 61-70, 2013.

33. Kwon KY, Ro JY, Singhal N, Killen DE, Sienko A, Allen TC, Zander DS, Barrios R, Haque A and Cagle PT: MUC4 expression in non-small cell lung carcinomas: Relationship to tumor histology and patient survival. Arch Pathol Lab Med 131: 593-598, 2007. 